\title{
Evaluation of residual stresses in lock valve elements of petrochemical productions
}

\author{
Elena Nikolaeva ${ }^{1, *}$ and Artem Mashukov ${ }^{1}$ \\ ${ }^{1}$ Irkutsk National Research Technical University, 83, Lermontov Str., Irkutsk, 664074, Russia
}

\begin{abstract}
Lock valves of the pipeline is an important and responsible product. It is designed to shut off the flow of liquid or gaseous fluid. During transportation ambient temperature reaches $400^{\circ} \mathrm{C}$, and the pressure over $30 \mathrm{MPa}$. Leakage of the fluid through the details and components of lock valves is not permitted. The batch of high-pressure valves was withdrawn after some time of its usage at the petrochemical enterprise. Premature wear of input branch pipe saddles was dis-covered. The cause of destruction of the input branch pipe saddles was erosion be-cause of abrasive particles, which are present in the working fluid. Locking node of the high-pressure armature is highly loaded element. The welding depositions are widely used to increase the strength of the valve locking node. It is established that under recommended heat treatment of the valve an ordered microstructure is formed and residual stress in the welding deposition zone is reduced. The article shows the relationship of residual stress with microstructure of the material. The magnitude of residual stresses in high-pressure valve locking node - in the brunch pipe saddle and the adjacent zones was determined by $\mathrm{x}$-ray method.
\end{abstract}

\section{Introduction}

"Stem-branch pipe" contact patches are the most destructible. Build-up welding is one of the main technological methods of increasing the reliability and service life of valve, and it is used in various industries $[1,2]$. Sealing surface of valves is hard-faced by alloys which are tearing, corrosion and erosion resistant in aggressive environments.

Building-up should provide not only good corrosion resistance but also abrasive wear resistance in the technological environments of petrochemical production through the useful life. Therefore, in the manufacture of sealing nodes of valves the corrosion resistant materials with high hardness are preferred [3].

\section{Materials and methods}

To strengthen the branch pipe saddle of high pressure valve DN25 [4], made of steel Fe- $09 \%$ C- $2 \% \mathrm{Mn}-1 \% \mathrm{Si}$, the hard-facing with flux-cored wire (fcw) EnDOtec DO*04 was carried out. Flax-cored wire EnDOtec DO*04 has advantages over other filler materials: it possesses high hardness and corrosion resistance. Also, the hard-faced layer must be resistant to thermal shock and temperature fluctuations, be quenchable and workable by cutting and not show a tendency to crack [5]. It is expected the hard-facing has high resistance the abrasive wear and "metal-metal" type friction, thermal wear hardness and deformation resistance [6], tempering resistance up to $650{ }^{\circ} \mathrm{C}$, scale resistance - up to $900^{\circ} \mathrm{C}$.
Figure 1 shows the section of valves, which were rein-forced by hard-facing.

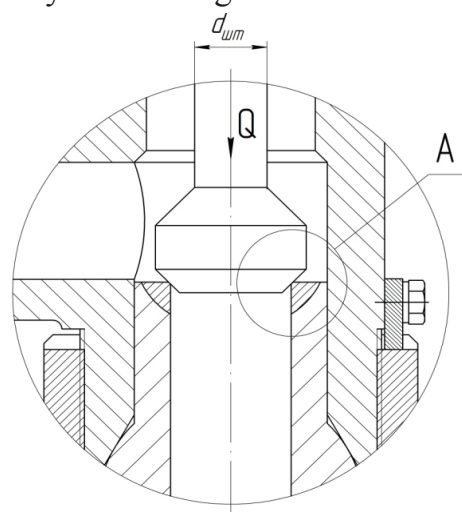

Fig. 1. The branch pipe and steam connection [7]: "A" section is reinforced by hard-facing.

Building-up was performed in three layers. Mechanical processing with hard-alloy tools was carried out after build-up welding. The authors of the publications $[8,9]$ in-vestigated the processes of metal cutting with different methods.

To improve the properties of building-up and branch pipe material the heat treat-ment was carried out: oil quenching from $1040^{\circ} \mathrm{C}$ and at $612{ }^{\circ} \mathrm{C}$. After quenching and tempering the branch pipe was cooled in oil. The quenching and tempering holding time is 1 hour.

The content of chemical elements in the welddeposited metal was determined by spectrophotometer UNIKO 1201, the contents of phosphorus and sulfur by analyzer METABAK CS-30 (see table. 1).

\footnotetext{
* Corresponding author: nicolaeva-ep@yandex.ru
} 
Table 1. Weight content of element, $\%$.

\begin{tabular}{|c|c|c|c|c|}
\hline $\mathbf{C}$ & $\mathbf{S i}$ & $\mathbf{M n}$ & $\mathbf{C o}$ & $\mathbf{C r}$ \\
\hline 0,13 & 0,23 & 0,26 & 9,81 & 8,69 \\
\hline $\mathbf{M o}$ & $\mathbf{W}$ & $\mathbf{S}$ & $\mathbf{P}$ & $\mathbf{F e}$ \\
\hline 2,0 & 0,08 & 0,008 & 0,011 & Balance \\
\hline
\end{tabular}

Branch pipes were investigated directly after mechanic processing, after build-up welding, after builddup welding and subsequent heat treatment. Branch pipes were cut on the machine Discotom-10. Samples for microanalysis were prepared using grinding-andpolishing system Tegramin-25. The microstructure was studied on an optical light microscope with magnification from 50 up to 1000 times. 5\% solution of nitric acid in ethyl alcohol was used to detect the microstructure of the base metal; for building-up - water $10 \%$ solution of nitric and hydrofluoric acid mixture was used. Microhardness was measured.

Residual stresses were measured on the inner surface of the branch pipe. X-ray diffractometer Xstress 3000 G3/G3R (figure 2) was used to measure residual stresses.

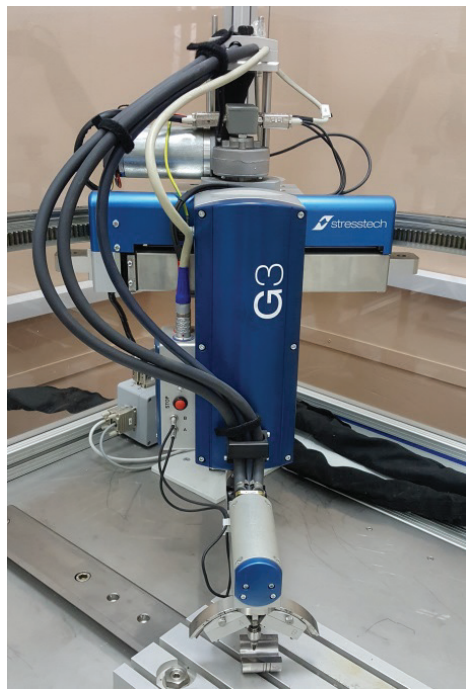

Fig. 2. Measurement of residual stresses on the inside of the branch pipe: the goniometer in position «omega».

Residual stresses in the building-up and the adjoining areas were determined by $x$-ray $\sin 2 \psi$-method [10, 11]. The optical scheme of the x-ray photography with "omega" goniometer configuration was used to record the position of the diffraction maximum. X-ray photography options were $\mathrm{Cr}-\mathrm{K} \alpha$ radiation. We used two detectors - A and $\mathrm{B}$. The angle of diffraction, 2 $\theta$, is $156.4^{\circ}$. Method for automated stress analysis is "Cross correlation" method; the Poisson's ratio is 0.3 ; elastic modulus is $210000 \mathrm{MPa}$.

Also the Barkhausen noise was measured. Application of the method is deter-mined by correlation between the amplitude of Barkhausen noise (mp) and micro-structure, hardness and residual stresses [12, 13$]$.
Digital Barkhausen noise analyzer Rollscan-300 was used. The authors successfully applied this device to control sur-face hardening by running rollers and shotshock treatment $[14,15]$. The amplitude of Barkhausen noise was determined on the same sections of the branch pipe that the re-sidual stresses. Measurement parameters of Barkhausen noise are voltage of $4 \mathrm{~V}$ and frequency of $80 \mathrm{kHz}$. Fig. 3 shows the recorder Rollscan 300 and the position of the sensor in the measurement.

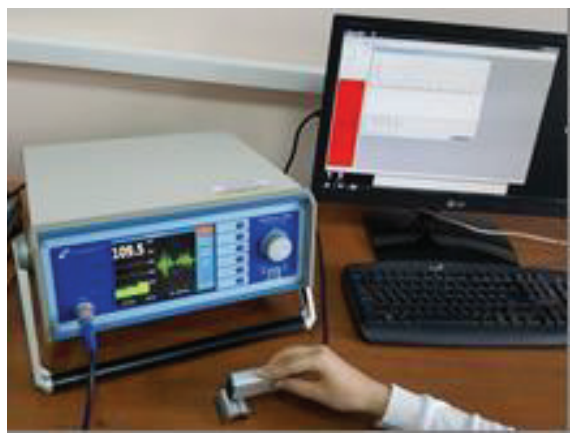

Fig. 3. Measurement of Barkhausen noise amplitude using the analyzer-Rollscan-300.

\section{Results and discussion}

The measurement results are shown in tables 2 and 3. In the build-up layer significant compressive stresses form, which are corresponded to minimal amplitude values of Barkhausen noise. Under the influence of heat treatment residual stresses increase. The lower level of compressive stress, the higher Barkhausen noise amplitude is.

Table 2. Amplitude of the Barkhausen noise in a branch pipe.

\begin{tabular}{|c|c|c|}
\hline \multirow{2}{*}{$\begin{array}{c}\text { The section } \\
\text { are taken } \\
\text { measurements }\end{array}$} & \multicolumn{2}{|c|}{ Barkhausen noise amplitude } \\
\cline { 2 - 3 } & $\begin{array}{c}\text { the branch pipe } \\
\text { with a building-up } \\
\text { before heat } \\
\text { treatment }\end{array}$ & $\begin{array}{c}\text { the branch pipe } \\
\text { with a building-up } \\
\text { after heat } \\
\text { treatment }\end{array}$ \\
\hline Building-up & 86 & 128 \\
\hline $\begin{array}{c}\text { Heat-affected } \\
\text { zone (HAZ) }\end{array}$ & 158 & 271 \\
\hline Base metal & 283 & 451 \\
\hline
\end{tabular}

It should be noted that the results of the noise measurements are influenced by the position of the sensor: along or across article. Therefore, to compare results in the same type of articles is necessary to adhere to the chosen schemes and the measurement parameters.

Residual stresses of the branch pipe after machining have been -398 MPa. 
Table 3. The residual stresses in a branch pipe.

\begin{tabular}{|c|c|c|}
\hline \multirow{2}{*}{$\begin{array}{c}\text { The section } \\
\text { are taken } \\
\text { measurements }\end{array}$} & \multicolumn{2}{|c|}{ Residual stresses, MPa } \\
\hline & $\begin{array}{c}\text { the branch pipe } \\
\text { with a building-up } \\
\text { before heat } \\
\text { treatment }\end{array}$ & $\begin{array}{c}\text { the branch pipe } \\
\text { with a building-up } \\
\text { after heat } \\
\text { treatment }\end{array}$ \\
\hline Building-up & -542 & -252 \\
\hline $\begin{array}{c}\text { Heat-affected } \\
\text { zone (HAZ) }\end{array}$ & -387 & -333 \\
\hline Base metal & -384 & -343 \\
\hline
\end{tabular}

The microstructure of building-up before heat treatment consists of dendrites, oriented in opposite of heat removal direction (Fig. 4, a).

High-alloy martensite (Fig. 4, b) is formed in the building-up after heat treatment.

Microstructure of build-up layers is very different. It takes place because of thermal effect on the build-up layer when each subsequent layer is over-laid on it.

Before thermal treatment the micro-hardness spread is observed in the build-up metal. Each new layer of building-up has higher micro-hardness than the previous layer: $533 \ldots 525 \mathrm{HV}$; 495... $502 \mathrm{HV}$; 488...494 HV - in the last top layer, second layer and first layer, respectively.

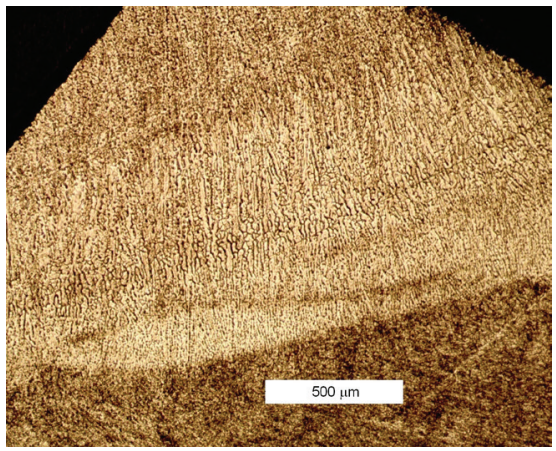

a

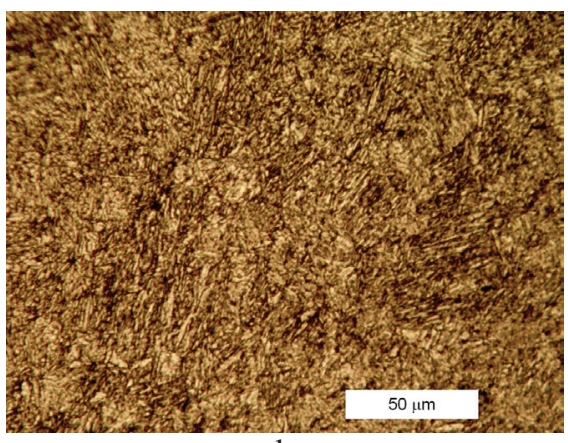

b

Fig. 4. The microstructure of building-up: a - before the heat treatment, dendrites, b - after heat treatment, high alloy martensite.

On the segment, which is adjoining to the buildingup, there is a crude ferrite-pearlite structure (widmanstatten) with micro-hardness of $167 \ldots 172 \mathrm{HV}$.
Throughout the micro-section there is a clear interface between the build-up and the base metal (Fig. 5, a). After heat treatment, the boundary between the base and build-up metal is "blurred" (Fig. 5, b), value and scatter of micro-hardness decrease, widmanstetter re-mains, but the grains become small, and the microstructure is generally more homo-geneous.
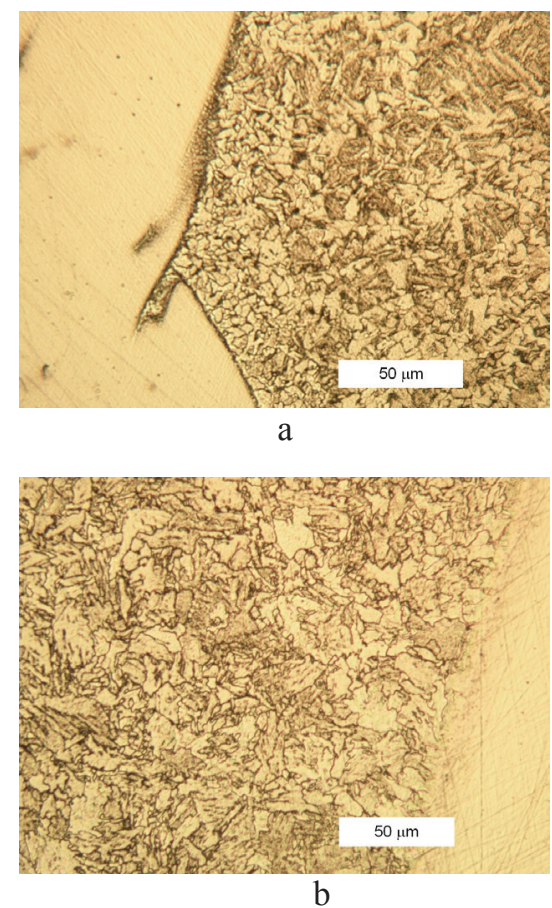

Fig. 5. The zone of transition from base metal to build-up metal: $\mathrm{a}$ - before heat treatment; $\mathrm{b}$ - after heat treatment.

The micro-hardness of the base metal after heat treatment slightly reduces to $161 \ldots 163 \mathrm{HV}$. The microhardness of building-up is: the first layer - $351 \ldots 352 \mathrm{HV}$, the second layer - 383...385 HV; the last top layer, 424...435 HV.

\section{Conclusion}

The highest value of residual stresses is defined on the inner surface of the branch pipe saddle in the contact zone of the "branch pipe-stem". The conducted research al-low to reveal a high level of compressive residual stress in building-up of branch pipe saddles of high pressure valves - on the order of -541,5 MPA.

It was confirmed a favorable effect of heat treatment, which improves the homo-geneity of the building-up microstructure and the adjoining layers of valve material.

Homogeneous microstructure provides reduce of residual stresses level by $50 \%$. It has a beneficial effect on the strength of built-up layer at the areas of "branch pipe-stem" contact and ensures the reliability of the pressure-tight joint.

The study confirmed the high degree of safety, which ensures reliability of struc-ture enhanced by building-up within a specified period of operation. Compressive stresses prevent the development of cracks near possible stress concentrators. 
Barkhausen noise method can be used for nondestructive examination (NDE) of build-up ferromagnetic materials, including building-up of branch pipes of high pres-sure valves.

Based on the conducted studies the serial production of the angular high-pressure lock valves DN 25 was set.

Authors are grateful to the Director General of OJSC «IrkutskNIIhimmash» A. Kuznetsov, head of the laboratory of the tightness department A. Gorbunov, employees of $\mathrm{O}$. Semenova, A. Lantin for supporting this research.

\section{References}

1. S. Zaydes, A. Mashukov, A. Tatarinov, Vestnik IrGTU, 5 (112), 37 (2016)

2. S. Gaisin, S. Zaides, Vestnik IrGTU, 6 (89), 45 (2014)

3. G. Gridin, Mater. of Sci. and tech. conf., Irkutsk, IX, 49 (2011)

4. G. Gridin, Chemical and Petroleum Engineering, 10, $26(2011)$

5. E. Eremin, A. Losev, Welding International, 3, 11 (2015)

6. Standard RF 053-2008

7. V. Pogodin, Shut-off valves for high operating parameters. Research and design (BrGU, Bratsk, 2016)

8. K. Ahmadi, A. Savilov, Int. J. of Machine Tools and Manufacture, 89, 208 (2015)

9. A. Nikolaev, IOP Conf. Ser.: Mater. Sci. Eng., 177, 012080 (2017)

10. V. Hauk, Structural and residual stress analysis by nondestructive methods: evaluation, application, assessment (Elsevier, Amsterdam, 1997)

11. L. Suominen, M. Khurshid, J. Parantainen, Procedia Eng. 5th Fatigue Design Conf. 66, 181 (2013)

12. E. Nikolaeva, D. Vlasov, IOP Conf. Ser.: Mater. Sci. Eng., 177, 012113 (2017)

13. E. Nikolaeva, D. Nikulin, MTSAM, 2 (50), 73 (2016)

14. E. Nikolaeva, E. Gridasova, V., Izv. SSC RAS, 17 (2-1), 125 (2015)

15. E Nikolaeva, Materials Science Forum, 870, 500 (2016)

16. E. Nikolaeva, Izv. SSC RAS, 15 (6-2), 428 (2013)

17. A. Karamyshev, A. Nikolaev, ISTU Bulletin of Youth, 3, 8 (2016) 